\title{
Variations in estimates of underweight, stunting, wasting, overweight and obesity in children from Argentina comparing three growth charts
}

\author{
Gisel Padula ${ }^{1,2, *}$, Analía I Seoane ${ }^{1}$ and Susana A Salceda ${ }^{3}$ \\ 'IGEVET - Instituto de Genética Veterinaria, Ing. Fernando N. Dulout, Facultad de Ciencias Veterinarias, \\ UNLP-CONICET, 60 y 118, 1900 La Plata, Argentina: ${ }^{2}$ IDIP - Instituto de Desarrollo e Investigaciones \\ Pediátricas 'Profesor Dr. Fernando Viteri', Hospital de Niños de La Plata (MS/CICPBA), La Plata, Argentina: \\ ${ }^{3}$ Departamento Científico de Antropología, Facultad de Ciencias Naturales y Museo, UNLP-CONICET, \\ La Plata, Argentina
}

Submitted 4 July 2011: Final revision received 14 February 2012: Accepted 21 February 2012: First published online 23 March 2012

\begin{abstract}
Objective: To compare estimates of underweight, stunting, wasting, overweight and obesity based on three growth charts.

Design: Cross-sectional study to estimate weight-for-age, length/height-for-age and weight-for-height comparing the 2006 WHO Child Growth Standards ('the WHO standards'), the 1977 National Center for Health Statistics (NCHS) international growth reference ('the NCHS reference') and the 1987 Argentine Pediatric Society Committee of Growth and Development reference ('the APS reference'). Cut-off points were defined as mean values $\pm 2 \mathrm{sD}$. Epi-Info software version $6 \cdot 0$ (Centers for Disease Control and Prevention) was used for statistical evaluations $\left(\chi^{2}, P \leq 0 \cdot 05\right)$. Setting: Greater La Plata conurbation, Buenos Aires, Argentina.

Subjects: A total of 2644 healthy, full-term children from 0 to 5 years of age.

Results: Prevalence of underweight was higher with the WHO standards than with the other references up to the first 6 months. For the rest of the ages, prevalence was lower with the WHO standards. Stunting prevalence was higher with the WHO standards at all ages. Prevalence of wasting was higher with the WHO standards compared with the NCHS reference up to the first 6 months and lower at 2-5 years of age. Overweight and obesity prevalences were higher with the WHO standards at all ages.

Conclusions: The new WHO standards appear to be a solid and reliable tool for diagnosis and treatment of nutritional diseases, also being the only one built with infants fed according to WHO recommendations. Therefore, our results support the decision of the National Ministry of Health about the utilization of the new WHO standards to monitor the nutritional status of Argentinean children aged less than 5 years.
\end{abstract}

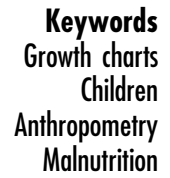

Different methods for field testing child nutritional status and assessing clinical, biochemical and anthropometric parameters have been described ${ }^{(1)}$. Because of their sensitivity, simplicity and low cost, anthropometric measurements allow the early detection of growth alterations that will later develop as signs and symptoms ${ }^{(2)}$.

At the individual level, growth charts are one of the simplest, most valuable and low-cost tools to measure the degree of satisfaction of child care and basic needs. At the population level, the use of global growth indicators and corresponding growth charts facilitates the assessment of child nutritional status and the evaluation of the effectiveness of interventions/treatments for growth problems, further supporting public health policy decision making ${ }^{(3)}$. Therefore, the assessment of child nutritional status and the implementation of health programmes greatly depend on the growth charts used ${ }^{(4)}$.

The use of an internationally valid reference to assess nutritional status and growth is very recent. The US National Center for Health Statistics (NCHS) growth reference $^{(5)}$, recommended by WHO for international application, had a series of technical weaknesses and limitations, and was inadequate to evaluate growth in breast-fed infants. In particular, this reference is inadequate because it is based predominantly on formula-fed infants, as are most national growth charts in use today ${ }^{(6)}$. In 1993 a WHO Expert Committee recommended the construction of a new international growth reference. The 1994 World Health Assembly endorsed the Expert Committee's recommendation to conduct a population-based study to 
collect anthropometric data for constructing the new reference $^{(7)}$. In 2006, the WHO released a set of new growth standards to assess the growth and development of children from birth up to the age of 5 years ${ }^{(8)}$. The study collected primary data of 8440 breast-feeding and healthy infants from widely differing ethnic backgrounds and cultural settings (Brazil, Ghana, India, Norway, Oman and the USA). These new standards have a prescriptive approach, reflecting how growth should be, and not merely describing how growth was on a given time and at a certain place ${ }^{(8)}$.

Until very recently, in Argentina there was consensus on the use of national references to assess children's nutritional status. This set of growth charts was developed and released jointly by the National Department of Infant and Maternal Health of the National Ministry of Health and the Argentine Pediatric Society (APS) ${ }^{(9)}$. They have been applied since 1987 and include the use of national weight and height charts for boys and girls from birth to maturity. Charts for 0- to 12-year-old boys/girls were built with data from studies performed in two prosperous provinces of Argentina during the 1960s and 1970s, including a longitudinal sample of 250 boys/girls aged 0-3 years from Gonnet, La Plata, a cross-sectional sample of 1800 boys/girls aged 4-12 years from La Plata, and another cross-sectional sample of 1800 boys/girls aged 4-12 years from Córdoba. Among the limitations of the study that developed the 0-3 year charts, we can mention the scarce number of boys/girls in the study cohorts, the high percentage of drop-outs during follow-up ( $>45 \%$ ) and the lack of representativeness at national level ${ }^{(3)}$.

The National Ministry of Health has now adopted the new WHO growth charts to monitor children from birth to 5 years of age, replacing the national references. Therefore, the aim of the present study was to compare estimates of underweight, stunting, wasting, overweight and obesity obtained with the new (2006) WHO Child Growth Standards ('WHO standards'), the old (1977) international growth reference ('the NCHS/WHO reference') ${ }^{(10)}$ and the national reference ('the APS reference'), in a sample of children under the age of 5 years from the Greater La Plata conurbation, Buenos Aires, Argentina.

\section{Materials and methods}

\section{Study design and sample}

A comparative cross-sectional study was conducted during the period October 2003-April 2005. Participants attended the health check of the Healthy Child Care Consultation Room at the Pediatric Service of the Hospital Interzonal 'Dr. Alejandro Korn' (Ministry of Health of the Province of Buenos Aires) located in Melchor Romero, La Plata, Argentina. This hospital was selected because of physicians' willingness to participate in the study. Participation was warranted by individual consent and voluntary participation.
We recruited, consecutively, 2644 children of both sexes aged $0-5$ years (Table 1 ). This number represents all children less than 5 years of age who attended the consultation on Mondays and Wednesdays. The sample size dwindles in older age groupings because of the differential frequency of health check visits. During the first year the consultation is monthly, in the second quarterly, semiannual in the third and then annually until 5 years of life. To facilitate the incorporation of healthy children, we included full-term babies ( $\geq 37$ weeks of gestation) without congenital malformations, chromosomal alterations, neurological, endocrine or metabolic disease, infections or any other problem at the beginning of the study.

\section{Population}

An estimated population of 120000 inhabitants receive health care at the Hospital Interzonal 'Dr. Alejandro Korn'. Figures concerning the population under 5 years of age are unknown ( $\mathrm{R}$ Marchetti, personal communication, 2006). The hospital is located in Melchor Romero, which presents the highest neonatal, post-neonatal and, consequently, infant mortality rates (3.92/10000, 4.79/10000 and $8 \cdot 72 / 10000$, respectively) in the Greater La Plata conurbation $^{(11)}$.

\section{Data collection}

Data collected included visit date, sex, birth date and anthropometric parameters. Weight was measured with a medical scale in kilograms and grams (100 g graduation; CAM, Manrique Hnos. SRL, Buenos Aires, Argentina). In all cases, children were weighed without clothes. Height was recorded in metres with a metal tape measuring rod (Seca 217; Smart BMI International Inc., Buenos Aires, Argentina), with the child barefoot and without socks. Anthropometric measurements were performed in accordance with the Growth and Development Guidelines released by the $\mathrm{APS}^{(12)}$. All data were recorded by a single experienced observer, following standardized procedures ${ }^{(12)}$.

Prevalence of undernutrition was calculated as the percentage of children with $Z$-score (the number of standard deviations an individual is from the reference mean) less than -2 according to the WHO standards and APS and NCHS references for the following parameters: weight-forage (underweight), height-for-age (stunting) and weightfor-height (wasting). Overweight and obesity were defined as high weight-for-height $(Z$-score $>2$ and $>3$ sD, respectively) ${ }^{(13)}$. WHO, APS and NCHS charts were used to compare prevalences of underweight and stunting, whereas prevalences of wasting, overweight and obesity were compared using the WHO standards and the NCHS reference. It was not possible estimate the prevalence of wasting, overweight and obesity with the APS reference due the lack of weight-for-height $Z$-score curves in the national reference. $Z$-scores for weight-for-age (WAZ), height-for-age (HAZ) and weight-for-height (WHZ) were assessed with the WHO standards and the NCHS reference, 
using the ANTHRO 2005 program (WHO, Geneva, Switzerland) ${ }^{(14)}$. WAZ and HAZ were determined with the APS reference using the Nutri 1.3:5 program (Ministry of Health, Buenos Aries, Argentina) ${ }^{(15)}$.

The study sample was divided into subgroups by age because of the imbalance in the distributions of both age and malnutrition. Accordingly, three age groups were formed: 0-6 months, 1 year and 2-5 years.

Data obtained with the three references were analysed statistically using Pearson's $\chi^{2}$ test in the Epi-Info software package version 6.0 (Centers for Disease Control and Prevention, Atlanta, GA, USA).

\section{Results}

Table 1 presents the age and sex distribution of the sample.

Table 2 shows the prevalence of underweight and stunting. Prevalence of underweight was significantly

Table 1 Distribution of the study sample by sex and age: children aged less than 5 years, La Plata, Argentina, October 2003-April 2005

\begin{tabular}{|c|c|c|c|}
\hline \multirow[b]{2}{*}{ Age } & \multicolumn{2}{|c|}{ Sex } & \multirow[b]{2}{*}{ Total } \\
\hline & Girls & Boys & \\
\hline 0-6 months & 515 & 522 & 1037 \\
\hline 1 year & 450 & 420 & 870 \\
\hline $2-5$ years & 384 & 353 & 737 \\
\hline Total & 1349 & 1295 & 2644 \\
\hline
\end{tabular}

higher with the WHO standards up to the first 6 months (WHO $v$. NCHS: $\chi^{2}=99 \cdot 58, P<0 \cdot 001$; WHO $v$. APS: $\left.\chi^{2}=81 \cdot 86, P<0 \cdot 001\right)$. For the rest of the ages, underweight prevalence was lower with the WHO standards than with the NCHS reference. Prevalence of underweight was significantly lower with the WHO standards than the APS reference at $2-5$ years of age $\left(\chi^{2}=5 \cdot 66, P<0 \cdot 05\right)$. When comparing NCHS and APS references, underweight prevalence was higher with the NCHS reference only at 1 year and significantly lower at $0-6$ months $\left(\chi^{2}=8 \cdot 2\right.$, $P<0 \cdot 01)$. Stunting prevalence was higher with the WHO standards than with the NCHS and APS references at all ages. This difference was significant up to the first 6 months (WHO $v$. NCHS: $\chi^{2}=37 \cdot 6, P<0 \cdot 001$; WHO $v$. APS: $\chi^{2}=7 \cdot 97, P<0 \cdot 01$ ) and at $2-5$ years (WHO $v$. APS: $\left.\chi^{2}=4.95, P<0.05\right)$. When comparing NCHS and APS references, the prevalence of stunting was higher with the NCHS reference at 2-5 years of age and significantly lower at 0-6 months $\left(\chi^{2}=11 \cdot 83, P<0 \cdot 001\right)$.

Table 3 presents the prevalences of wasting, overweight and obesity. Prevalence of wasting was significantly higher up to the first 6 months $\left(\chi^{2}=25 \cdot 57, P<0 \cdot 001\right)$ and lower at 2-5 years of age with the WHO standards than with the NCHS reference. Overweight prevalence was significantly higher with the WHO standards compared with the NCHS reference at all ages ( $0-6$ months: $\chi^{2}=21 \cdot 48, P<0 \cdot 001$; 1 year: $\chi^{2}=62 \cdot 06, P<0 \cdot 001 ; 2-5$ years: $\left.\chi^{2}=30 \cdot 73, P<0 \cdot 001\right)$. Prevalence of obesity was higher with the WHO standards than with the NCHS reference at all ages, but only significantly at 1 year $\left(\chi^{2}=6 \cdot 44, P<0 \cdot 01\right)$.

Table 2 Frequency and prevalence of underweight and stunting by age, comparing the WHO standards, the NCHS reference and the APS reference: children aged less than 5 years $(n$ 2644), La Plata, Argentina, October 2003-April 2005

\begin{tabular}{|c|c|c|c|c|c|c|c|c|c|c|c|c|}
\hline \multirow[b]{3}{*}{ Age group } & \multicolumn{6}{|c|}{ Underweight } & \multicolumn{6}{|c|}{ Stunting } \\
\hline & \multicolumn{2}{|c|}{ WHO } & \multicolumn{2}{|c|}{$\mathrm{NCHS}$} & \multicolumn{2}{|c|}{ APS } & \multicolumn{2}{|c|}{ WHO } & \multicolumn{2}{|c|}{$\mathrm{NCHS}$} & \multicolumn{2}{|c|}{ APS } \\
\hline & $n$ & $\%$ & $n$ & $\%$ & $n$ & $\%$ & $n$ & $\%$ & $n$ & $\%$ & $n$ & $\%$ \\
\hline 0-6 months & 148 & $14 \cdot 3$ & 13 & $1 \cdot 3$ & 32 & $3 \cdot 1$ & 113 & $10 \cdot 9$ & 40 & $3 \cdot 9$ & 76 & $7 \cdot 3$ \\
\hline 1 year & 16 & $1 \cdot 8$ & 21 & $2 \cdot 4$ & 12 & $1 \cdot 4$ & 47 & $5 \cdot 4$ & 41 & $4 \cdot 7$ & 35 & $4 \cdot 0$ \\
\hline $2-5$ years & 18 & $2 \cdot 4$ & 28 & $3 \cdot 8$ & 35 & $4 \cdot 8$ & 48 & $6 \cdot 5$ & 40 & $5 \cdot 4$ & 29 & 3.9 \\
\hline Total & 182 & 6.9 & 62 & $2 \cdot 3$ & 79 & $3 \cdot 0$ & 208 & $7 \cdot 9$ & 121 & $4 \cdot 6$ & 140 & $5 \cdot 3$ \\
\hline
\end{tabular}

WHO standards, 2006 WHO Child Growth Standards; NCHS, 1977 National Center for Health Statistics international growth reference; APS reference, 1987 Argentine Pediatric Society Committee of Growth and Development reference.

Table 3 Frequency and prevalence of wasting, overweight and obesity by age, comparing the WHO standards and the NCHS reference: children aged less than 5 years ( $n$ 2644), La Plata, Argentina, October 2003-April 2005

\begin{tabular}{|c|c|c|c|c|c|c|c|c|c|c|c|c|}
\hline \multirow[b]{3}{*}{ Age group } & \multicolumn{4}{|c|}{ Wasting } & \multicolumn{4}{|c|}{ Overweight } & \multicolumn{4}{|c|}{ Obesity } \\
\hline & \multicolumn{2}{|c|}{ WHO } & \multicolumn{2}{|c|}{$\mathrm{NCHS}$} & \multicolumn{2}{|c|}{ WHO } & \multicolumn{2}{|c|}{$\mathrm{NCHS}$} & \multicolumn{2}{|c|}{ WHO } & \multicolumn{2}{|c|}{$\mathrm{NCHS}$} \\
\hline & $n$ & $\%$ & $n$ & $\%$ & $n$ & $\%$ & $n$ & $\%$ & $n$ & $\%$ & $n$ & $\%$ \\
\hline 0-6 months & 46 & $4 \cdot 4$ & 9 & 0.9 & 72 & 6.9 & 27 & $2 \cdot 6$ & 6 & 0.6 & 4 & 0.4 \\
\hline 1 year & 10 & $1 \cdot 2$ & 7 & 0.8 & 73 & $8 \cdot 4$ & 5 & 0.6 & 9 & $1 \cdot 0$ & 1 & $0 \cdot 1$ \\
\hline $2-5$ years & 12 & $1 . \overline{6}$ & 20 & $2 \cdot 7$ & 38 & $5 \cdot 2$ & 3 & 0.4 & 3 & 0.4 & 0 & 0.0 \\
\hline Total & 68 & $2 \cdot 6$ & 36 & $1 \cdot 4$ & 183 & 6.9 & 35 & $1 \cdot 3$ & 18 & 0.7 & 5 & 0.2 \\
\hline
\end{tabular}

WHO standards, 2006 WHO Child Growth Standards; NCHS, 1977 National Center for Health Statistics international growth reference. 


\section{Discussion}

In the present study we analysed differences in the estimated prevalences of underweight, stunting, wasting, overweight and obesity in children aged 0 to 5 years, comparing three growth charts. As already reported ${ }^{(16)}$, it is difficult to compare and evaluate indicators due to the lack of consistency and coincidence among classification criteria, choice of reference populations and cut-off values ${ }^{(17-19)}$.

The assessment of growth patterns comparing the WHO standards and the APS reference showed a higher prevalence of underweight during the first half of infancy (0-6 months) and of stunting at all ages with the former. Similar results were obtained in two recent studies comparing the new WHO growth charts with the APS reference ${ }^{(9,20)}$. In Argentina, validation of the clinical utility of the WHO standards showed that whereas the percentage of underweight breast-fed children was higher with the WHO standards, that of stunted breast-fed children was higher with the APS reference ${ }^{(3)}$. It should be noted that these results may be found because the age groups and cut-offs were established with different criteria for the APS reference than for the WHO standards.

Compared with the NCHS reference, growth pattern assessment based on the WHO standards showed a higher prevalence of underweight during the first half of infancy (0-6 months), of stunting at all ages, of wasting during the first 18 months and of overweight and obesity at all ages. Using the NCHS reference, the prevalence of overweight would not be a health problem, and that of obesity would not be a health problem with either chart. This is consistent with the observations of a WHO group of experts who noted that the prevalence of undernutrition (underweight, stunting and wasting) during early life was higher with the WHO standards as compared with the NCHS reference. In fact, de Onis et al. obtained a higher prevalence of underweight in breast-fed infants based on the WHO standards ${ }^{(4)}$. Likewise, stunting and overweight rates were higher with the WHO growth charts in all age groups, and estimates of wasting were higher with the WHO standards up to 2 years of age. Similar results were reported in other studies $^{(21,22)}$. On the other hand, in a validation study ${ }^{(3)}$ comparing the WHO standards and the NCHS reference, higher rates of underweight and wasting were obtained with the latter and higher stunting, overweight and obesity figures with the former.

The APS Growth and Development Committee suggested that the change of charts implied a change in the assessment of the main anthropometric and nutritional parameters used to determine population prevalence, without concomitant changes in population health conditions ${ }^{(20)}$.

Main differences for all indicators were observed in children under the age of 6 months. In general, during the first 6 months after delivery, breast-fed children have higher weight and height than formula-fed children, with a lower growth from 6 months onwards. From this age, charts that were made based on data obtained from formula-fed children tend to underestimate the growth of breast-fed children ${ }^{(23)}$. One of the main contributions of the new WHO standards to paediatric follow-up is that breast-fed children under the age of 1 year will not be classified as having a deficit in growth ${ }^{(9)}$.

It can therefore be noted that significant conceptual, methodological and operational differences among the three references account for the differences observed. As already mentioned, local data and the US data are descriptive, whereas those from WHO samples are prescriptive; i.e. the choice of individuals was based on predefined criteria, namely healthy children, fed according to WHO feeding recommendations and living in healthy environments favouring growth ${ }^{(20)}$. The number of cases in APS charts was too small during the first 3 years. Moreover, the new WHO charts use complex statistical models that normalize asymmetric distributions and particularized smoothing techniques to each growth variable ${ }^{(9,20)}$.

Considering that differences in populations are socioenvironmental rather than genetic ${ }^{(24)}-$ a fact confirmed in the WHO study by the lack of differences in height among populations from the six sites studied ${ }^{(8)}$ - the WHO charts should be taken as a positive growth and development goal by ministries, public health institutions and agencies devoted to child health, growth and development. At population level, underestimation of the prevalence of undernutrition using the national references and the old international charts would exclude children from food aid programmes and/or therapeutic approaches.

Among the strengths of the present study we can mention that it is one of the first comparing underweight, stunting, wasting, overweight and obesity estimates with the WHO standards, the NCHS and the APS references, using cut-off values recommended by WHO, in a population of Argentinean children under the age of 5 years; further, all records were made by a single observer, previously trained with standardized protocols to minimize inter-observer errors. Although it would have been valuable to record other socio-cultural indicators, this could be part of another stage of the study.

\section{Conclusions}

Major differences in the estimated prevalence of underweight and stunting were observed in children less than 6 months of age with the three growth charts. In this group, frequencies were higher when the WHO standards were used. Also, the prevalence of wasting, overweight and obesity was higher with these curves. The new WHO standards appear to be a solid and reliable tool for diagnosis and treatment of nutritional diseases, also being the only one built with infants fed according to WHO recommendations. Therefore, our results support the decision of the National Ministry of Health about the utilization of 
the new WHO growth charts to monitor the nutritional status of Argentinean children from birth up to the age of 5 years. Moreover, their use will allow comparison of results of population studies from different countries.

\section{Acknowledgements}

The study was supported by a grant from CONICET. No conflicts of interest were declared. G.P. participated in the design of the study, data collection, processing of the data, interpretation of the results and writing of the first draft of the manuscript. A.I.S. and S.A.S. participated in data interpretation and in revising the paper critically for substantial intellectual content. The study protocol was presented to and approved by the Teaching and Research Committee of the Hospital Interzonal 'Dr. Alejandro Korn'. The authors are grateful to the authorities of the Hospital Interzonal de Agudos y Crónicos 'Dr. Alejandro Korn' (Dr E. Melía, Dr R. Marchetti and Dr N. Zelaschi) for their support to perform this research work; the Pediatric Service of the Hospital; Dr D. Fryd and S. Federici; and nurses Nora, Susana, María Luisa, Cristina and Andrea for their collaboration. They also thank all children and their parents for participation in the study. Special thanks are extended to D. Horacio González for a critical reading of the manuscript and A. Di Maggio for manuscript translation and editing.

\section{References}

1. Waterlow JC (1996) Malnutrición proteico-energética. Publicación Científica no. 555. Washington, DC: Organización Panamericana de la Salud, Organización Mundial de la Salud.

2. Padula G (2008) Malnutrición Infantil. Diagnóstico antropométrico y consecuencias cromosómicas, p. 142. La Plata: Al Margen.

3. Sguassero Y, Moyano C, Aronna A et al. (2008) Validación clínica de los nuevos estándares de crecimiento de la OMS: análisis de los resultados antropométricos en niños de 0 a 5 años de la ciudad de Rosario, Argentina. Arch Argent Pediatr 106, 198-204.

4. de Onis M, Onyango AW, Borghi E et al. (2006) Comparison of the World Health Organization (WHO) Child Growth Standards and the National Center for Health Statistics/WHO international growth reference: implications for child health programmes. Public Health Nutr 9, 942-947.

5. Hamill PV, Drizd TA, Johnson CL et al. (1979) Physical growth: National Center for Health Statistics percentiles. Am J Clin Nutr 32, 607-629.

6. de Onis M, Garza C, Onyango AW et al. (2009) Les standards de croissance de l'Organisation mondiale de la santé pour les nourrissons et les jeunes enfants. Arch Pediatr 16, 47-53.

7. de Onis M, Garza C, Victora CG et al. for the WHO Multicentre Growth Reference Study Group (2004) The WHO Multicentre Growth Reference Study: planning, study design, and methodology. Food Nutr Bull 25, Suppl. 1, S15-S26.

8. WHO Multicentre Growth Reference Study Group (2006) WHO Child Growth Standards: Length/Height-for-Age, Weight-for-Age, Weight-for-Length, Weight-for-Height and
Body Mass Index-for-Age: Methods and Development. Geneva: WHO.

9. Lejarraga H (2003) Estándares de Crecimiento en la Argentina. In Simposio: Uso de estándares y referencias. Actas $1^{a}$ Jornadas Nacionales de Auxología; available at http://www.sap.org.ar/staticfiles/actividades/congresos/ congre2003/auxologia/confer.pdf

10. de Onis M, Garza C, Onyango AW et al. (2007) Comparison of the WHO child growth standards and the CDC 2000 growth charts. J Nutr 137, 144-148.

11. Observatorio de Calidad de Vida La Plata (2001) Diagnóstico de Calidad de Vida en el Partido de La Plata, pp. 53-73. La Plata: Secretaría de Extensión Universitaria UNLP.

12. Sociedad Argentina de Pediatría, Comité de Crecimiento y Desarrollo (2001) Guías para la evaluación del crecimiento, $2^{\mathrm{a}}$ ed. Buenos Aires: Sociedad Argentina de Pediatría.

13. Waterlow JC (1973) Note on the assessment and classification of protein-energy malnutrition in children. Lancet 2, 87-89.

14. WHO ANTHRO (2005) Software for Assessing Growth and Development of the World's Children. Geneva: WHO; available at http://www.who.int/childgrowth/software/en/

15. Ministerio de Salud de la Nación Argentina, Dirección de Maternidad e Infancia/Dirección de Información, Ministerio de Salud de la Provincia de Neuquén/Programa Materno Infantil, Provincia de Buenos Aires (2000) Nutri 1.3 Program. http://www.msal.gov.ar/htm/site/promin/ UCMISALUD/index.htm (accessed December 2007).

16. Padula G \& Salceda SA (2008) Comparación entre referencias de las prevalencias de sobrepeso y obesidad, estimadas a través del Índice de Masa Corporal, en niños de Argentina. ALAN 58, 330-335.

17. Bejarano I, Dipierri J, Alfaro E et al. (2005) Evolución de la prevalencia de sobrepeso, obesidad y desnutrición en escolares de San Salvador de Jujuy. Arch Argent Pediatr 103, 101-109.

18. Flegal KM, Ogden CL, Wei R et al. (2001) Prevalence of overweight in US children: comparison of US growth charts from the Center for Disease Control and Prevention with other reference values for body mass index. Am J Clin Nutr 73, 1086-1093.

19. Sweeting HN (2007) Measurement and definitions of obesity in childhood and adolescence: a field guide for the uninitiated. Nutr J 6, 32 .

20. Sociedad Argentina de Pediatría, Comité Nacional de Crecimiento y Desarrollo (2008) La Sociedad Argentina de Pediatría actualiza las curvas de crecimiento de niñas y niños menores de 5 años. Arch Argent Pediatr 106, 462-467.

21. Nuruddin R, Lim MK, Hadden WC et al. (2009) Comparison of estimates of under-nutrition for pre-school rural Pakistani children based on the WHO standard and the National Center for Health Statistics (NCHS) reference. Public Health Nutr 12, 716-722.

22. Schwarz NG, Grobusch MP, Decker ML et al. (2008) WHO 2006 child growth standards: implications for the prevalence of stunting and underweight-for-age in a birth cohort of Gabonese children in comparison to the Centers for Disease Control and Prevention 2000 growth charts and the National Center for Health Statistics 1978 growth references. Public Health Nutr 11, 714-719.

23. Lejarraga H, Abeyá Gilardon E, Anigstein C et al. (2007) Referencias y estándares de crecimiento en la Argentina. Consideraciones del Grupo ad hoc para el análisis de las tablas de la Organización Mundial de la Salud y su uso en la Argentina. Arch Argent Pediatr 105, 159-166.

24. Bustos P, Amigo H, Muñoz SR et al. (2001) Growth in indigenous and nonindigenous Chilean school children from 3 poverty strata. Am J Public Health 91, 1645-1649. 